\title{
Uptake of immunisations in low birthweight infants
}

\author{
J ROPER AND S DAY
}

Department of Clinical Epidemiology, London Hospital Medical College, London

SUMMARY The timing of immunisations for preterm infants is controversial. Because of the statement by the British Paediatric Association/Joint Committee on Vaccination and Immunisation Liaison group that immunisations should normally begin three months after the date of birth, the records of all infants born in 1984 and currently (June 1986) resident in the London Borough of Newham were studied to find out if this recommendation was being implemented. Subjects were divided into groups by birth weight and where possible by gestational age. Cumulative uptakes by age of any component of the first and third triple immunisations, and of the pertussis component, were plotted separately. Comparison of uptake of the first course showed a considerable initial delay for infants weighing less than $2000 \mathrm{~g}$ at birth compared with heavier babies, but by 18 months the coverage was almost identical. This difference was not evident for the third course. A similar delay was apparent when infants of 37 weeks' gestation or less were compared with babies born at full term, though recording of gestational age was incomplete. Final overall uptake was poor for all groups. Differences among groups in numbers consenting were not an important factor.

Informing those responsible for giving the immunisations of these findings has stimulated their interest in improving practice by implementing the recommendations.

The London Borough of Newham is a deprived urban borough with a multiracial population. The proportion of children in the population is high and movement in and out of the borough is considerable. The overall uptake of immunisations in Newham is low, but of particular concern is that babies of low birth weight or short gestation may be especially poorly protected.

The age at which preterm infants should begin their primary course of immunisations is controversial $^{1}$ but the current recommendation endorsed by the British Paediatric Association/Joint Committee on Vaccination and Immunisation Liaison Group is that immunisation of these infants should normally begin three months after their date of birth. ${ }^{2}$ This regimen is likely to produce an acceptable immune response without increasing the risk of adverse reaction. ${ }^{3}$

We have compared the uptake of immunisations for babies of low birth weight and for preterm infants with that of their peers of normal birth weight. In view of the particular concern about pertussis immunisation and the vulnerability of small infants (especially during the recent epidemic), uptake of the pertussis antigen was studied separately as were other components of the triple immunisation.

\section{Methods}

Data on all infants born in 1984 and currently (June 1986) resident in Newham were studied. The regional child health computer register provided the most complete and accurate data on immunisations available ${ }^{4}$ including those given to infants before they moved to the borough. These data were used to produce graphs of uptake by age using SASGRAPH and infants were subdivided into groups by birth weight and by gestation.

Data for birth weight were complete, and accurate to within $10 \mathrm{~g}$. A limit of $2000 \mathrm{~g}$ was used to separate low birthweight infants $(n=395)$ from normal $(n=3426)$ infants, as in 1984 this was the weight below which an infant would automatically be admitted to the special care baby unit-an event that leads to a baby being labelled as 'different' from other infants.

Data for gestation were only available for 3502 infants. Omission was more likely for low birthweight infants, 313 of 395 low birthweight infants and six of 3426 normal birthweight infants having no record of length of gestation (table 1). Comparisons were first made between infants born at full term (38 or more completed weeks' gestation), preterm infants (32-37 completed weeks' gestation) and 
very preterm infant (31 completed weeks' gestation or less); numbers in the last group, however, were too small to permit informative comparisons.

Other factors which might have influenced uptake were studied. The most obvious of these was ethnic origin ${ }^{5}$ but recording of this was so inaccurate that analysis could not be performed.

The frequency of consent for immunisations and whether or not this consent included pertussis was

Table 1 Gestational ages and birth weights of groups studied

\begin{tabular}{lcc}
\hline $\begin{array}{l}\text { Gestational } \\
\text { age (weeks) }\end{array}$ & $\begin{array}{l}\text { No (\%) } \\
\text { in low } \\
\text { birthweight } \\
\text { group }\end{array}$ & $\begin{array}{l}\text { No (\%) } \\
\text { in normal } \\
\text { birthweight } \\
\text { group }\end{array}$ \\
\hline$<31$ & $22(6)$ & $1(0 \cdot 03)$ \\
$32-37$ & $52(13)$ & $352(10)$ \\
$>38$ & $8(2)$ & $3067(90)$ \\
Not recorded & $313(79)$ & $6(0 \cdot 18)$ \\
\hline Total & $395(100)$ & $3426(100)$ \\
\hline
\end{tabular}
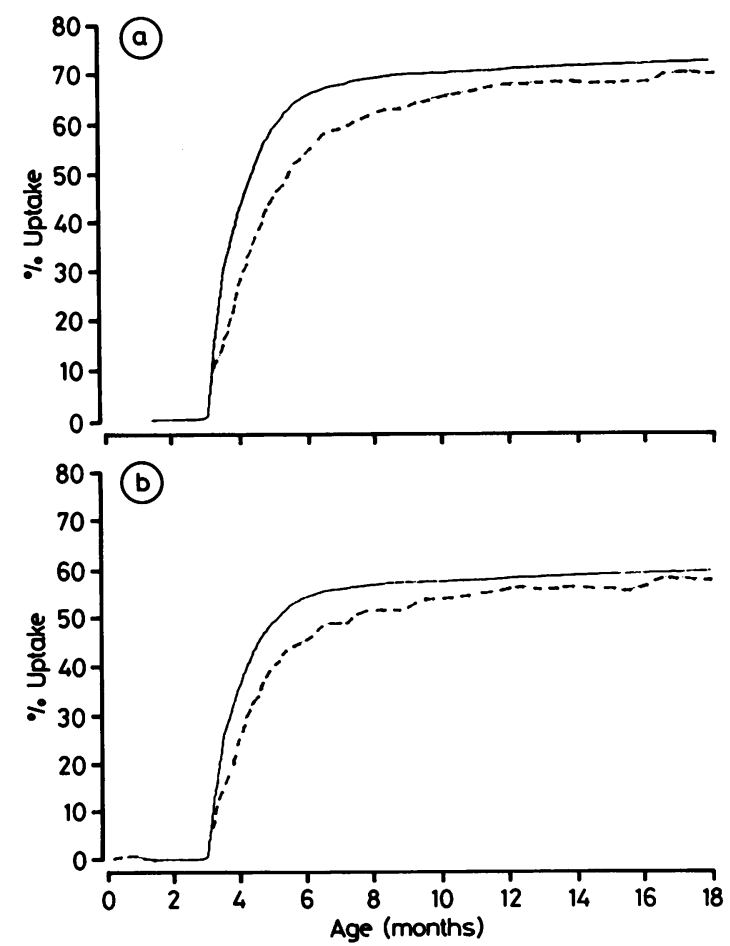

Fig 1 Eventual uptake by birth weight of first course of vaccination (a) for any antigen and (b) for pertussis alone. Solid lines indicate normal infants and broken lines low birthweight infants. also studied. Immunisation was discussed with the family by the health visitor shortly after birth and a consent form signed if the parents were willing to have the child immunised. The intention to include or exclude any particular antigen was shown on this form. This intention was recorded in the computer file but a further consent was required at the time of immunisation. The frequency with which consent was initially given for immunisation, with and without pertussis, was determined for each birthweight group, and compared with the actual number of immunisations given.

\section{Results}

When uptake was compared by birth weight, the eventual uptake of the first course with or without pertussis vaccination was similar (fig 1), being $71 \%$ for low birthweight infants and $72 \%$ for normal birthweight infants for any antigen, $58 \%$ for low birthweight infants and $59 \%$ for normal birthweight infants for pertussis, but the immunisations were significantly delayed for the low birthweight
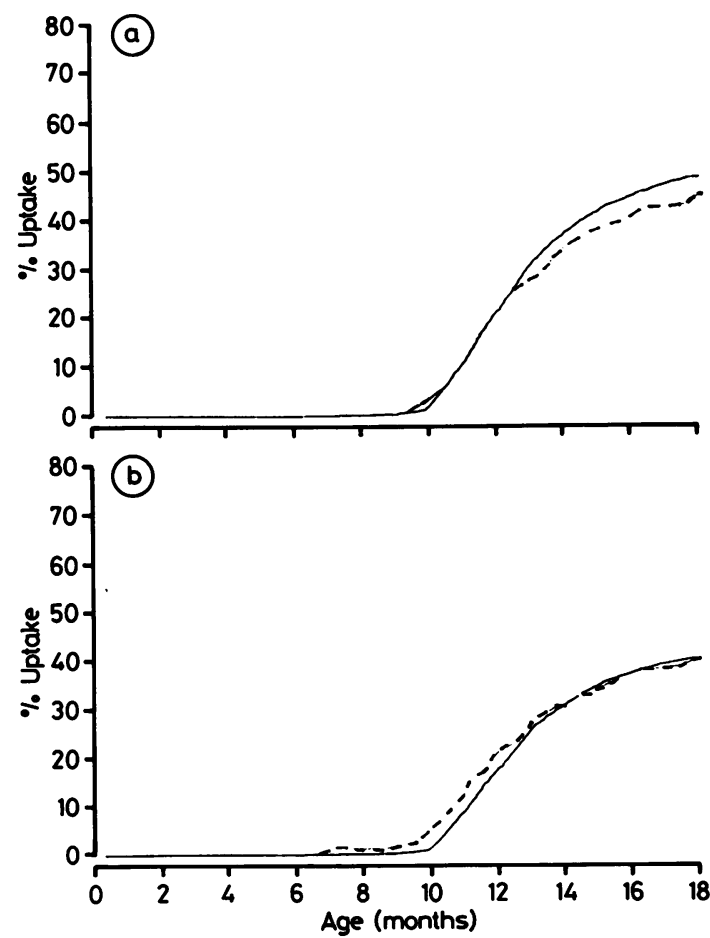

Fig 2 Eventual uptake by birth weight of third course of vaccination (a) for any antigen and (b) for pertussis alone. Solid lines indicate normal infants and broken lines low birthweight infants. 
infants. The percentage of infants receiving any injection within one month of the recommended starting age of 3 months was low-30\% for low birthweight infants and $41 \%$ for normal birthweight infants.

There was no difference between the two groups in the timing of the third course (fig 2). Rather than indicating a 'catch up' by the low birthweight
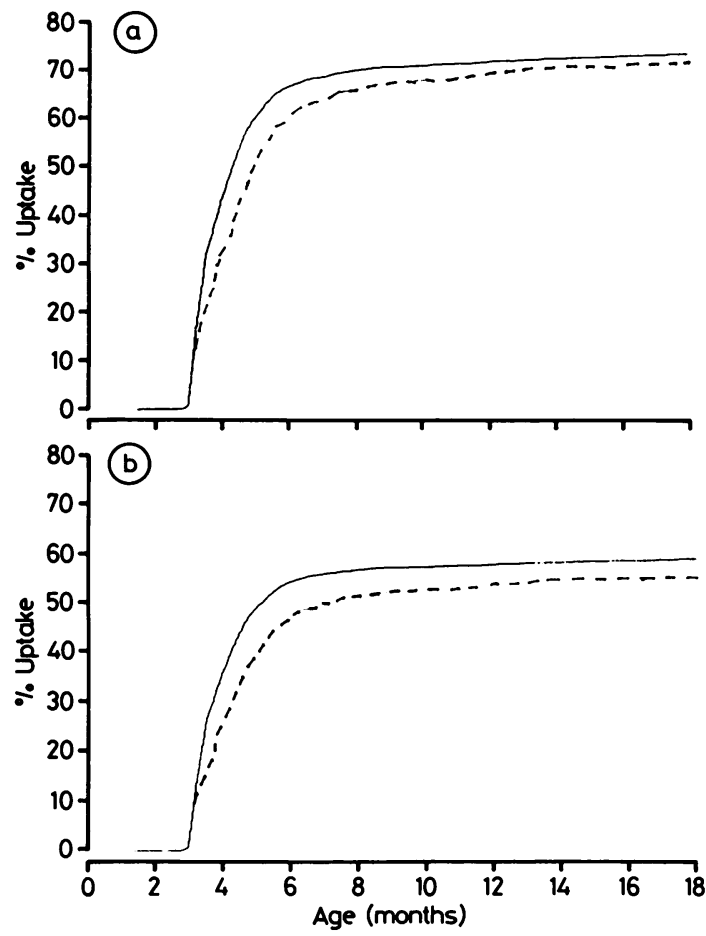

Fig 3 Uptake by gestational age of first course of vaccination (a) for any antigen and (b) for pertussis alone. Solid lines indicate normal infants and broken lines low birthweight infants. infants this was because the normal birthweight infants received their third dose later than was recommended, only $11 \%$ of each group were immunised within one month of the suggested age of 10 months.

When uptake was compared for gestation of age a similar picture emerged (fig 3); $31 \%$ of preterm infants and $41 \%$ of those born at full term started their immunisations within one month of the recommended age. Eventual uptake for pertussis seemed to be less for preterm infants $(56 \%$ compared with $60 \%$ ), but analysis by birth weight (including only those for whom gestational age was known) showed a similar difference suggesting that this discrepancy may have arisen from incomplete recording of data.

Overall rates of consenting to immunisation were similar in both birthweight groups (table 2), and a similar proportion of each subsequently failed to be immunised.

\section{Discussion}

The results confirmed the suspicion that the smallest and therefore most vulnerable infants were not being protected as well as possible. Protection of young infants against pertussis by prenatal transfer of maternal antibody is not adequate; the only means of protecting infants is by active immunisation. Pertussis is a distressing illness at any age, but if the baby is small and immature, it is more likely to develop serious complications, and possibly die. In an area in which many older children are not immunised and the potential pool of infection is therefore large (especially during an epidemic such as occurred recently) young infants are particularly at risk, and probably remain so until the second dose of pertussis immunisation has been given. ${ }^{3}$ In order to minimise this risk it is wise to begin immunisations as soon as they are both effective and safe.

The similar rates of consent and eventual uptake

Table 2 Numbers consenting to and receiving immunisations in two groups studied

\begin{tabular}{lll}
\hline & $\begin{array}{l}\text { No (\%) in low } \\
\text { birthweight group } \\
(n=395)\end{array}$ & $\begin{array}{l}\text { No (\%) in normal } \\
\text { birthweight group } \\
(n=3426)\end{array}$ \\
\hline Babics with consent to receive immunisation & $386(98)$ & $3350(98)$ \\
Those with such consent who received immunisation & $279(72)$ & $2477(74)$ \\
Those with such consent whose immunisation included pertussis & $227(59)$ & $2046(61)$ \\
Babies with consent to receive pertussis antigen & $339(86)$ & $2898(85)$ \\
Those with such consent who received any other immunisation & $232(68)$ & $2113(73)$ \\
Those with such consent who received pertussis antigen & $222(65)$ & $1985(69)$ \\
Babies with consent to receive immunisation excluding pertussis & $47(12)$ & $452(13)$ \\
Those with such consent who recived any other immunisation & $45(96)$ & $364(81)$ \\
Those with such consent who received pertussis antigen & $5(11)$ & $61(14)$ \\
\hline
\end{tabular}


for both birthweight groups suggest that the problems of delivery are not related to concern about contraindications to immunisation as such, but to inappropriate worries about immunising infants below a certain gestational age or weight. This cannot be confirmed by this study, but anecdotal evidence from parents is common.

In order to improve coverage, particular emphasis is now being laid on the recommendation that all infants should begin their immunisations at 3 months of age. Senior community medical officers and senior community nurses are being told this, and in addition there is a written recommendation in the summary that is sent to the general practitioner and to the community clinic for every baby discharged from the special care baby unit. Information is included about the presence or absence of specific contraindications to receiving the pertussis antigen that have arisen in the neonatal period. The subject is also discussed with the parents by staff in the special care units to ensure that their choices are made in the light of current recommendations.

This effort is already meeting with some success; in future we intend to perform similar analyses for infants born in later years to measure this success.

We thank the staff of the North East Thames regional computer centre and the University of London computer centre for their help and advice.

\section{References}

1 Lingham S, Miller C. Pateman J, et al. Immunisation of preterm infants. Br Med J 1986;292:1183-5.

2 Report of the British Pacdiatric Association/Joint Committee on Vaccination and Immunisation Liaison Group. London: British Pacdiatric Association. 1985.

${ }^{3}$ Berenbaum JC. Daft A. Anolik R, et al. Response of pre-term infants to diphtheria-tetanus-pertussis immunisation. $J$ Pediatr 1985:107:284-8.

4 Alberman E, Watson E, Mitchell P. Day S. The development of performance and cost indicators for preschool immunisation. Arch Dis Child 1986;61:251-6.

5 Baker MR. Bandaranayake E. Schweiger MS. Differences in rate of uptake of immunisation among ethnic groups. $\mathrm{Br}$ Med J 1984;288:1075-8.

Correspondence to Dr J Roper. Department of Clinical Epidemiology. London Hospital Medical College. London E1 1BB.

Accepted 21 September 1987 